\title{
PROPOSTA DE UMA METODOLOGIA PARA O ENSINO DA ESTRUTURA E FUNÇÃO DAS PROTEÍNAS NA DISCIPLINA BIOQUÍMICA.
}

\begin{abstract}
Resumo:
INTRODUÇÃO: A Bioquímica é uma disciplina fundamental para uma formação superior crítica e reflexiva do estudante da área biológica e da saúde. A Bioquímica é uma ciência ampla, a qual lida com assuntos complexos e abstratos, o que muitas vezes dificulta seu entendimento pelos alunos e acaba contribuindo para um alto percentual de reprovação na disciplina. 0 objetivo do presente trabalho foi desenvolver uma metodologia de ensino/aprendizagem para minimizar as dificuldades de entendimento do conteúdo didático, explorar as potencialidades de aplicação desse conteúdo e facilitar o estudo da estrutura e função das proteínas na disciplina Bioquímica. METODOLOGIA: Com o intuito de introduzir e contextualizar conceitos bioquímicos a respeito da estrutura e função das proteínas, cinco estratégias foram propostas: confecção de modelos de biomoléculas com materiais de baixo custo; uso do corpo como ferramenta pedagógica para a fixação de conceitos básicos; elaboração de um roteiro de procedimentos de laboratório com substâncias reagentes do dia a dia para demonstração prática do conteúdo teórico; contextualização do tema em relação ao cotidiano do aluno e sua futura prática profissional; e uso da internet de forma complementar ao processo de ensino/aprendizagem iniciado em sala de aula. A metodologia proposta foi realizada em uma turma de 35 alunos do $2^{\circ}$ período de graduação de enfermagem e os resultados foram avaliados através da percepção do professor e do preenchimento, pelos alunos, de um questionário elaborado especificamente para este estudo. RESULTADOS E DISCUSSÃO: Foram gastos 150 minutos para a realização das estratégias elaboradas na metodologia. Na opinião do professor, o conteúdo pôde ser transmitido de uma forma fácil e os alunos se mostraram abertos e interessados com a exposição. Dos dezoito alunos que responderam ao questionário, todos foram unânimes em elogiar os modelos elaborados para a demonstração visual do conteúdo teórico. Dois alunos relataram alguma dificuldade quanto ao entendimento do conteúdo ao término dos procedimentos. Estratégias adicionais podem ser utilizadas a fim de corrigir esse déficit residual. CONSIDERAÇÕES FINAIS: A metodologia desenvolvida foi considerada uma proposta apropriada para favorecer o estudo de proteínas, podendo ser utilizada como uma alternativa complementar pelos professores dessa disciplina. Diferentes metodologias empregadas no ensino de bioquímica podem contribuir para uma maior motivação e compreensão por parte do aluno.

Palavras Chaves: Ensino, Bioquímica, Proteínas
\end{abstract}

\section{A proposal for a teaching methodology concerning protein structure and function in the discipline of Biochemistry}

\begin{abstract}
:
INTRODUCTION: Biochemistry is a basic discipline that propitiates a critic and reflexive formation of higher education students in the biological and health area. Biochemistry is an ample science that deals with complex and abstract issues, which are commonly difficult for the students to understand, and therefore contributes to high percentages of failure in the discipline. The objectives of the present study were to develop a teaching/learning methodology to minimize the difficulties regarding the understanding of the didactic contents, to explore the potentialities related to the application of these contents to the practice, and to facilitate the study of the protein structure and function in the discipline of biochemistry. METHODOLOGY: Aiming to introduce and contextualize the biochemistry concepts related to the protein structure and function, five strategies were proposed: the confection of bimolecular models made of low cost materials; the use of the body as a pedagogical tool aiming at the
\end{abstract}


memorization of basic concepts; the development of a script for laboratorial procedures regarding reagent substances related to the day-to-day routine, including practical demonstration of the theoretical contents; the contextualization of the biochemistry in relation to the quotidian life of the student and his/her future professional practice; and the use of the internet as a complementary device of the teaching/learning process that was initiated at the classroom. The proposed methodology was applied to the 35 students of the second semester class of the graduation course of nursing. The results were evaluated based on the perception of the teacher and the answers given by the students in a questionnaire specifically designed for this study. RESULTS AND DISCUSSION: The time necessary to implement the strategies presented at methodology was 150 minutes. According to the teacher, the contents were taught in an easy manner and students were receptive and interested in the explanations. All the 18 students that answered the questionnaire praised the models designed to visually demonstrate the theoretical contents. Two students reported some difficulties related to the understanding of the contents even at the end of the procedures. Additional strategies can be used to correct this remaining deficit. FINAL CONSIDERATIONS: The methodology developed in this paper seems to be an appropriate proposal to assist the study of proteins and can be used as an additional alternative by biochemistry teachers. Different methodologies used for biochemistry teaching can contribute to better motivation and comprehension by students. Keywords: Teaching, Biochemistry, Proteins 


\section{INTRODUÇÃO}

Qual a semelhança entre o chifre de um rinoceronte, um vaga-lume e uma hemácia? Todos contêm proteínas [1]. Proteínas são polímeros de resíduos de s-aminoácidos unidos por ligações covalentes específicas, denominadas ligações peptídicas. Os - aminoácidos são moléculas que apresentam um grupo amino e um grupo carboxila ligados a um átomo de carbono central (carbono alfa). O que diferencia um aminoácido de outro é a sua cadeia lateral (Fórmula 1) [1,2]. Todas as proteínas são formadas a partir da união de apenas 20 tipos de aminoácidos diferentes; os quais podem ser agrupados em cinco categorias de acordo com as características de suas cadeias laterais em pH fisiológico (apolares alifáticos, apolares aromáticos, polares, carregados positivamente e carregados negativamente).

$$
\begin{array}{r}
\mathrm{COOH} \\
\mathrm{H}_{2} \mathrm{~N}-\mathrm{C}_{\bar{*}} \mathrm{H} \\
\left.\right|_{\mathbf{R}}
\end{array}
$$

Fórmula 1: Representação genérica de um ^-aminoácido. Legenda: $C^{*}$ : carbono alfa; $\mathrm{H}_{2} \mathrm{~N}$ : grupo amino; $\mathrm{COOH}$ : ácido carboxílico; $\mathrm{H}$ : átomo de hidrogênio; R: cadeia lateral

As proteínas apresentam resíduos de ^-aminoácidos, pois estes perdem um átomo de hidrogênio do grupo amino e uma hidroxila do grupo carboxila durante as formações das ligações peptídicas [1]. Esses polímeros naturais formados pela união de saminoácidos são as macromoléculas mais abundantes em nosso organismo e apresentam as mais diversas funções biológicas. As funções que as proteínas exercem dependem do arranjo espacial de seus átomos (estrutura tridimensional); desse modo, é de se esperar que as proteínas apresentem muitas formas diferentes [2].

O que mantém a forma final (nativa) das proteínas são as interações entre as cadeias laterais de seus resíduos de aminoácidos e destes com o solvente [1,2]. Essas interações são basicamente de quatro tipos: interações iônicas, ligações de hidrogênio, interação hidrofóbica e ponte dissulfeto. As interações iônicas são interações eletrostáticas entre aminoácidos que apresentam grupos ionizáveis em suas cadeias laterais. Ligações de hidrogênio são interações moleculares formadas quando átomos de hidrogênio e elementos muito eletronegativos (oxigênio, nitrogênio e flúor) interagem. Interações hidrofóbicas são as interações que ocorrem entre cadeias laterais apolares, acontecendo normalmente no interior da proteína, quando ela se encontra em ambiente aquoso. Ponte dissulfeto, por sua vez, é a ligação covalente formada entre dois átomos de enxofre das cadeias laterais de dois aminoácidos cisteína [3].

Qualquer fator que interfira na interação entre as cadeias laterais dos aminoácidos poderá resultar na alteração da conformação da proteína. A alteração da forma tridimensional de uma proteína, que resulte na perda de sua função, é chamada de desnaturação [1].

Tais informações, triviais para um professor de bioquímica, embora abranjam um conteúdo restrito no universo da disciplina, podem parecer assustadoras e incompreensíveis para um estudante que acaba de ter contato com a matéria. 0 estudo de bioquímica envolve assuntos complexos e abstratos, o que, muitas vezes, dificulta a apreciação dos alunos por seus conteúdos [4,5]. O número de alunos reprovados na disciplina Bioquímica é expressivo e uma parte desses alunos repete a disciplina já cursada por mais de uma vez $[5,6]$. Exige-se do estudante, para que ele entenda as estruturas das proteínas, que ele faça uma representação mental, em uma 
perspectiva tridimensional, de um conteúdo que lhe foi apresentado em duas dimensões, seja no livro, na lousa ou projetado em uma superfície em uma aula expositiva.

Além disto, para o entendimento da bioquímica são necessárias noções básicas de química e biologia [6], porém, diversos alunos iniciam os seus estudo com um déficit de entendimento desses conhecimentos ou misturando os significados de alguns conceitos, como o de ligações covalentes ou de forças de Van Der Waals. Tentar ensinar proteínas a um estudante que carece de informações sobre as interações entre os átomos, por exemplo, é como pedir para que uma pessoa comece a subir uma escada a partir do quinto degrau. É possível que algumas pessoas dêem um pulo e alcancem, mas outras irão se machucar tentando e, muitas vezes, desistirão.

Para uma aprendizagem efetiva, é importante que os conteúdos ministrados façam sentido para os alunos. Paulo Freire afirma que o processo de aprendizagem deveria ser iniciado com temas significativos para a vida do estudante [7]. Molander [8] demonstrou que os alunos tendem a aprender melhor quando trabalham com itens evolvidos em sua rotina e já conhecidos.

A disciplina Bioquímica é uma matéria do ciclo básico de diversos cursos de graduação da área biológica e da saúde, como: Ciências Biológicas, Educação Física, Enfermagem, Farmácia, Fisioterapia e Nutrição [6].

A Bioquímica é fundamental para uma formação superior crítica e reflexiva do indivíduo, além de suprir a fundamentação básica para a compreensão de outros conteúdos, mas, que muitas vezes, pode ser prejudicada pelo anseio dos alunos em vivenciar situações práticas [9].

A partir dessas considerações, o presente trabalho teve como objetivo apresentar propostas de metodologias para trabalhar as dificuldades de ensino/aprendizado da matéria, explorar as potencialidades do conteúdo e, deste modo, buscar facilitar o ensino da bioquímica e motivar os alunos para o estudo da estrutura e função das proteínas.

\section{MÉTODOLOGIA}

Reuniões informais entre alguns professores das disciplinas de Química e de Bioquímica de diferentes instituições de ensino superior de Belo Horizonte sinalizaram para a necessidade de desenvolvimento de novas metodologias de ensino que permitissem introduzir e contextualizar o conteúdo de bioquímica relativo à estrutura e função das proteínas.

A partir desses encontros foram então propostas cinco estratégias para tornar a visualização da estrutura dessas biomoléculas mais concreta para os alunos e possibilitar a análise de suas propriedades, reforçando os conceitos básicos relativos ao tema e contextualizando o conteúdo da disciplina nos aspectos relacionados ao cotidiano dos estudantes e à sua futura prática profissional. São elas:

I ) O desenvolvimento de modelos tridimensionais de biomolécula, utilizando materiais de baixo custo, para o estudo dos níveis de organização estrutural das proteínas

II ) O uso do corpo como ferramenta didática para ilustrar as interações entre as partes de uma molécula de proteína. 
III ) A realização de uma prática de laboratório com substâncias do dia a dia utilizadas como reagentes, direcionando a discussão dos resultados para um interpretação bioquímica.

IV ) A pesquisa e exposição em sala de aula das implicações do conteúdo de estrutura e função das proteínas em atividades do cotidiano e em doenças, para a contextualização dos conhecimentos.

V ) A busca e o repasse de endereços eletrônicos na internet, relacionados ao tema, como proposta para a complementação do processo de ensino-aprendizagem iniciado em sala.

\section{DETALHAMENTO DAS ESTRATÉGIAS E ROTEIRO DE AULA}

\section{I ) Desenvolvimento de modelos tridimensionais de biomolécula, utilizando materiais de baixo custo, para o estudo dos níveis de organização das proteínas}

I.a ) Materiais para a confecção dos modelos", \#

- 3 alfinetes com a cabeça preta;

- 3 alfinetes com a cabeça amarela;

- 4 alfinetes com a cabeça vermelha;

- 4 alfinetes com a cabeça verde;

- 5 alfinetes com a cabeça azul;

- 5 alfinetes com a cabeça branca;

- 1 gominha elástica (elástico de dinheiro);

- 4 metros de fio encapado na cor amarela (cabo elétrico para condução de eletricidade, adquirido em lojas de material elétrico);

- Alicate (para cortar o fio em 3 partes de $20 \mathrm{~cm}$ e uma parte de 3,40m);

- 1 caneta para enrolar o fio no formato de uma alfa hélice.

I.B ) MÉTODOS PARA A CONFECÇÃO DOS MODELOS E SEQÜÊNCIA DA AULA

Com os materiais citados foram confeccionadas quatro estruturas:

\section{$1^{\text {a) }}$ Seqüência de aminoácidos}

Para a elaboração da primeira estrutura, foi utilizado um segmento do fio de cobre maleável encapado com plástico amarelo, com $20 \mathrm{~cm}$ de comprimento, tendo sido afixado um alfinete preto em uma extremidade e um alfinete amarelo na outra (Figura 1a).

$1 *$ - A quantidade de material pode variar dependendo do tamanho da molécula montada e do número de cadeias laterais representadas.

2 \# - O custo total do material descrito foi inferior a 5 reais. 

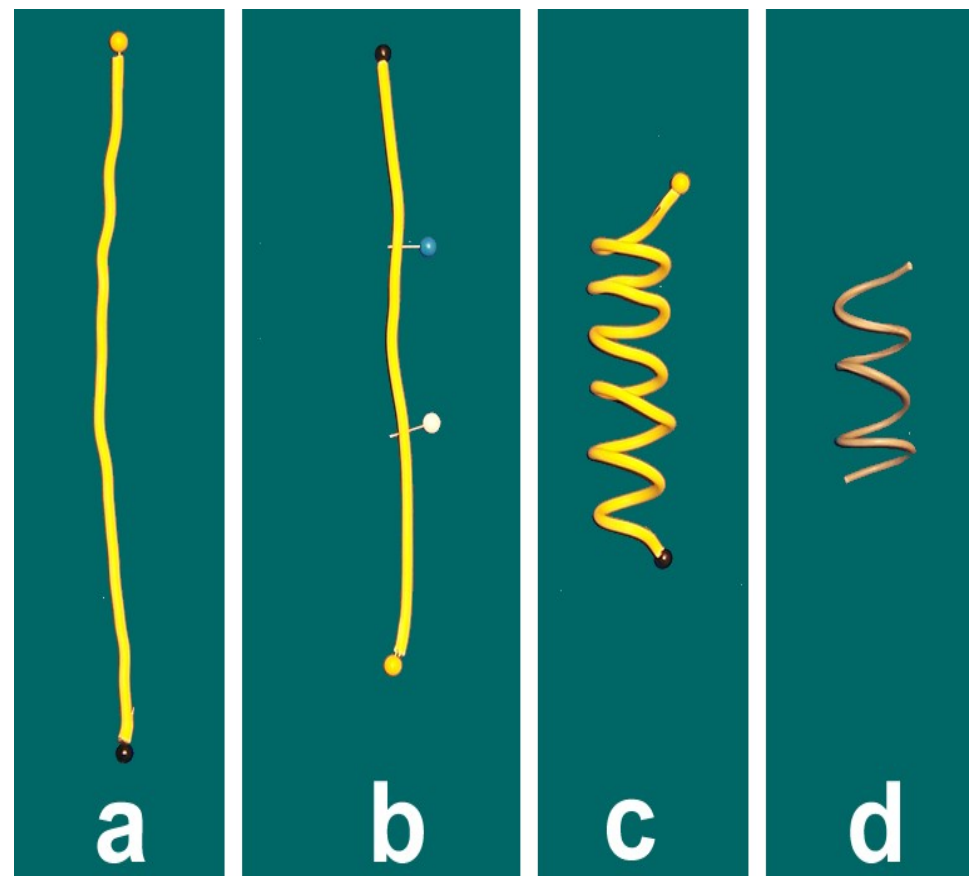

Figura 1. Modelos de segmentos de biomoléculas. a) representação esquemática de uma seqüência de aminoácidos; b) representação de uma seqüência de aminoácidos com duas cadeias laterais simbolizadas; c) representação de uma alfa hélice; d) representação de uma alfa hélice montada em um fio encapado de menor rigidez.

Essa estrutura (Fig.1a) foi apresentada aos alunos e foi dito que o fio encapado representava as ligações peptídicas, o alfinete preto representava a carboxila terminal e o alfinete amarelo a amina terminal.

Após isto foi feita a seguinte pergunta: se as proteínas apresentam as funções fisiológicas mais diversas em nosso organismo e a função da proteína depende de sua forma, como essa estrutura linear pode representar as proteínas?

Foi então explanado que é possível que as proteínas tenham outra conformação e questionado aos alunos: como vocês acham que é a conformação das proteínas em nosso organismo?

O modelo da seqüência de aminoácidos (fio amarelo com alfinetes nas extremidades) era então repassado ao aluno que se prontificasse a responder voluntariamente à pergunta anterior. Era solicitado que ele modelasse o fio no formato que acreditasse que fossem as proteínas.

É comum que os alunos façam uma curvatura no fio ou tentem simular uma espiral. Nesse momento, novos conceitos são inseridos.

\section{$\left.2^{\mathrm{a}}\right)$ Representação das cadeias laterais}

Considerando que a primeira estrutura confeccionada representava uma cadeia de aminoácidos, ficaram ausentes do modelo partes importantes dos resíduos de aminoácidos, as quais são diretamente responsáveis pela sua diferenciação: as cadeias laterais.

Foi então apresentada a segunda estrutura utilizada na aula, similar à anterior, mas com a inserção de dois alfinetes atravessando o revestimento do fio, um azul e um branco, conforme mostra a Figura $1 \mathrm{~b}$.

Como na região central do fio encontra-se o condutor de eletricidade, feito de cobre, que é intransponível, os alfinetes, que representam os radicais dos aminoácidos, 
foram fixados nos fios encapados na periferia do fio, conforme pode ser observado na figura 2.

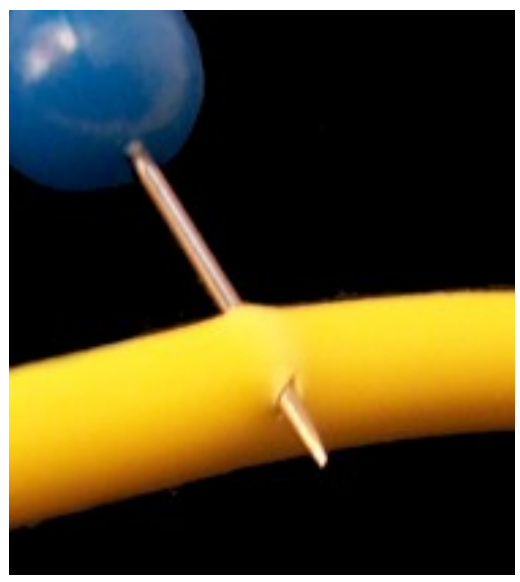

Figura 2 - Detalhe da fixação do alfinete no fio encapado

Um cuidado merece consideração é no manuseio dos modelos. Como eles são feitos com alfinetes fincados, os alunos devem ser advertidos para terem atenção ao manuseá-los para evitar acidentes.

$\mathrm{Na}$ segunda estrutura montada (Figura 1b), um alfinete azul foi afixado para representar a cadeia lateral de um resíduo de aminoácido do grupo carregado positivamente, como, por exemplo, a cadeia lateral da arginina, e o alfinete branco a cadeia lateral de um resíduo de aminoácido do grupo carregado negativamente, como, por exemplo, a cadeia lateral do aspartato.

\section{II) O USO DO CORPO COMO FERRAMENTA DIDÁTICA PARA ILUSTRAR AS INTERAÇÕES ENTRE OS ÁTOMOS DA MOLÉCULA DE PROTEÍNA}

Com o modelo da seqüência de aminoácido modelada pelo aluno e o fio encapado com a representação de duas cadeias laterais em mãos, conceitos básicos importantes para o entendimento da forma da proteína, como o de ligação covalente e o de interação intramolecular foram apresentados, empregando o corpo para fazer uma analogia entre as interações.

Foi então questionado: por que o aluno fez uma curvatura no fio que representava uma proteína? Como poderia ser realmente a conformação das proteínas em nosso organismo?

Para responder a isto, os alunos foram solicitados a ficar de pé e darem as mãos, um ao lado do outro. Uma analogia entre as ligações químicas e o aperto de mãos dos alunos foi feita então: as pessoas representaram os aminoácidos de uma proteína e as mãos dadas representaram, especificamente, as ligações covalentes entre os átomos (ligações peptídicas). O aluno de uma extremidade da fileira foi então orientado a ir conversar com o colega da outra extremidade, sem largar a mão, causando uma curvatura na molécula. A conversa foi interpretada como uma forma interação intramolecular mais fraca que uma ligação covalente (mãos dadas), mas capaz de alterar a forma da molécula. 
Uma molécula na realidade não conversa, o que mantêm sua curvatura são outras formas de interações. No modelo com a representação das cadeias laterais está afixado um alfinete azul, representando um aminoácido com um radical carregado positivamente e um alfinete branco, representado um aminoácido carregado negativamente, de forma que eles se atraem (interação iônica); da mesma maneira que o aluno da ponta que conversa, de mão dada, com um aluno da outra ponta.

\section{$\left.3^{a}\right)$ Alfa hélice}

A terceira estrutura representada nos modelos desenvolvidos para a aula foi a de uma alfa hélice, onde foi montada uma estrutura similar à primeira, mas após a fixação dos alfinetes representando a amina terminal e a carboxila terminal, essa estrutura foi enrolada em uma caneta, a qual é retirada após o modelamento, restando apenas a forma apresentada na Figura 1c.

Esse novo modelo foi utilizado para apresentar a estrutura secundária da proteína e, também, para mostrar que outras formas de interações, além das interações iônicas, estarão presentes nas proteínas contribuindo para seu formato.

\section{$4^{a}$ ) Proteína 3D}

Finalmente, o último modelo confeccionado foi o da estrutura tridimensional de uma proteína. Para a montagem desse modelo foi utilizado todo o fio restante $(3,4$ metros). No modelo da proteína foram colocados dois segmentos em espiral simulando alfa-hélices e dois segmentos simulando folhas betas pregueadas, os quais foram montados colocando pedaços de fios estendidos em paralelo em alguns trechos da estrutura. Em outros locais do fio foram feitas curvaturas e a forma final da molécula de proteína pode ser observada na figura 3. 


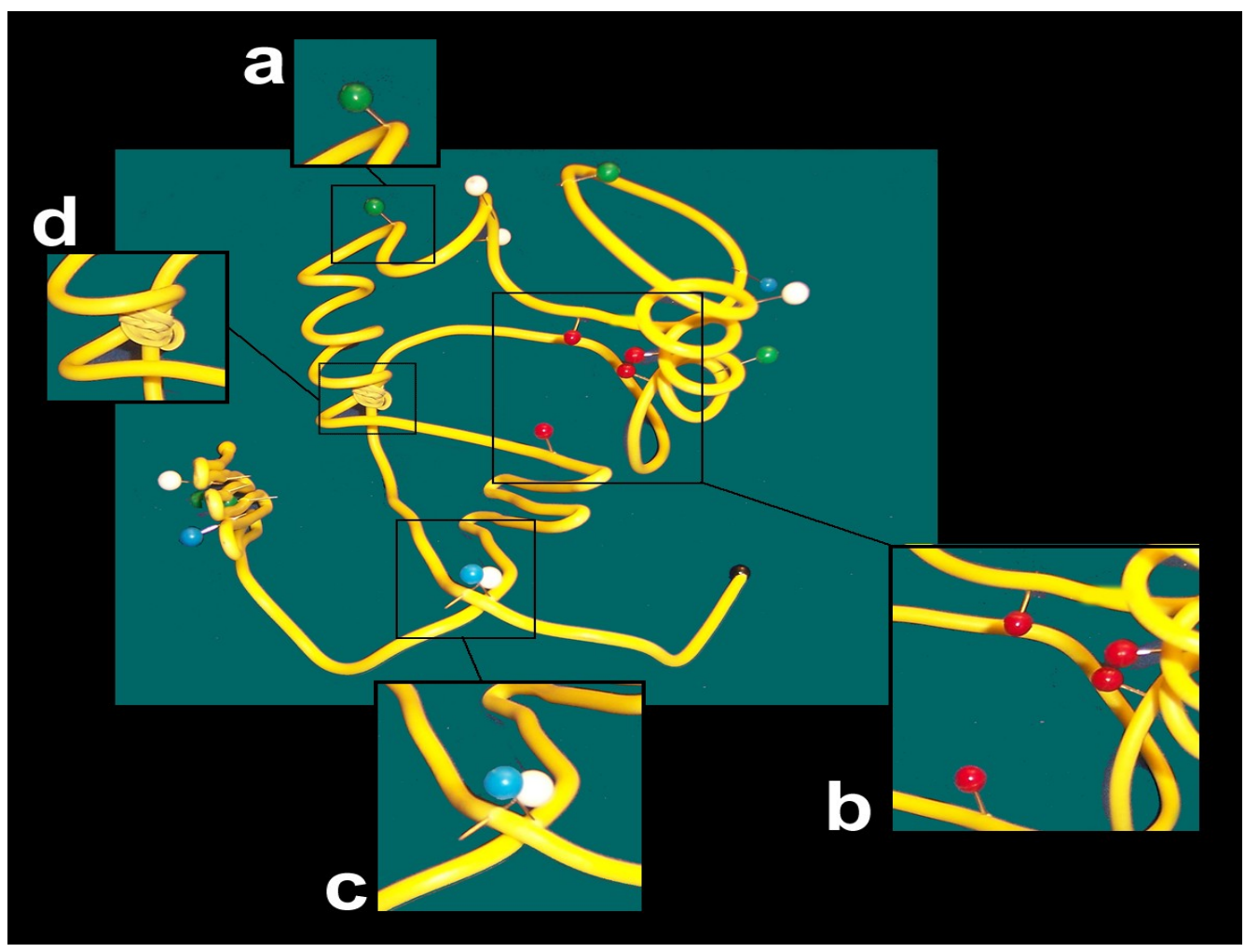

Figura 3 - Foto do modelo tridimensional da proteína. Em sentido horário: a) representação da localização dos aminoácidos com radicais polares (verde) na superfície externa da proteína; b) representação da interação entre os aminoácidos com radicais apolares (vermelhos) na região interna da proteína; c) representação de uma interação iônica entre radicais carregados com cargas opostas (azul:carregado positivamente e branco:carregado negativamente); d) representação de uma ponte dissulfeto entre aminoácidos cisteína (elástico de dinheiro).

Além das contorções no fio encapado, foram afixados alfinetes em pontos específicos para representar as cadeias laterais dos aminoácidos e para demonstrar as interações que ocorrem entre elas, conforme detalhado abaixo. As cores utilizadas representaram os seguintes grupos:

- Verde: representaram os aminoácidos polares, os quais se encontravam na superfície externa do modelo da proteína. (Figura 3a);

- Vermelho: representaram os aminoácidos com radicais apolares, e se encontravam no interior do modelo da proteína. (Figura 3b);

- Azul: representaram as cadeias laterais dos aminoácidos carregados positivamente;

- Branco: representaram as cadeias laterais dos aminoácidos carregados negativamente. Em um ponto específico da proteína, onde dois segmentos se encontravam, foi colocados um alfinete branco (carregado negativamente) e um alfinete azul (carregado positivamente) para demonstrar a atração entre eles (interação iônica). (Figura 3c);

Além disto no modelo da proteína, também foi amarrado um elástico de dinheiro (Figura 3d) ligando dois segmentos do modelo de proteína, simulando uma ponte dissulfeto entre aminoácidos cisteína. 


\section{III ) Realização de uma prática de laboratório com substâncias do dia a dia utilizadas como reagentes, direcionando a interpretação dos resultados para um raciocínio bioquímico}

Após a exposição do modelo aos alunos, para que eles assimilassem algumas das implicações práticas dos níveis de organização das proteínas, foi elaborada uma aula prática para visualização da coagulação de proteínas do leite, intitulada: "Pesquisa qualitativa dos constituintes do leite". Foi entregue aos alunos um roteiro da aula prática, com os materiais necessários, métodos e perguntas para discussão dos procedimentos (Tabela $1 \tilde{\text { ) }}, * * 34$

Tabela 1: Roteiro proposto para a aula prática

TÍTULO: PESQUISA QUALITATIVA DOS CONSTITUINTES DO LEITE

\section{OBJETIVOS}

- Separar constituintes do leite por precipitação;

- Estimar alguns dos constituintes do leite.

\section{MATERIAIS}

Béquer;

Bastão de vidro;

Filtro de papel;

Leite de saquinho;

Ácido acético (5\%).

\section{MÉTODOS}

1. Coloque $50 \mathrm{ml}$ de leite no béquer;

2. Adicione o ácido acético gota a gota, com agitação lenta e constante até que o leite coagule (use o bastão de vidro para agitar);

3. Deixe em repouso por 5 minutos e filtre o sobrenadante;

4. Transfira o material contido no filtro de papel para o béquer.

\section{PERGUNTAS}

a) O que você acha que é esse material que precipitou? Como você explicaria essa resposta que você observou?

3 ‡ - Para a realização dessa prática os alunos já têm que saber manipular os materiais de laboratório e estarem habituados com conceitos de $\mathrm{pH}$ e titulação de aminoácidos

4 **. A aula prática proposta foi adaptada do "Roteiros de Aulas Práticas e Apoio Teórico de Bioquímica", da Pontifícia Universidade Católica de Minas Gerais, desenvolvido por Fernando Costa Amaral e Neuza de Mesquita Antonino. 
b) Que cor ficou o líquido sobrenadante (compare com o leite e com a água destilada pura)? Por quê?

A substância que precipitou não deve ser mencionada aos estudantes, que a partir do conteúdo previamente repassado sobre a estrutura e função da proteína, deve deduzir que substância foi essa que se separou do solvente e decantou; e porque isto ocorreu.

Outros procedimentos podem ser inseridos na prática, bem como outras perguntas, como: Foi alterada a estrutura primária ou terciária da proteína? O que aconteceria se colocássemos limão no leite? Defina precipitação. E outras.

\section{IV) Exposição em sala de aula das implicações do conteúdo de estrutura e função das proteínas em atividades do cotidiano e em patologias, para a contextualização dos conhecimentos.}

Foram discutidas desnaturações das proteínas, usando como exemplo a desnaturação da albumina, proteína presente na clara dos ovos. O aquecimento do ovo causa uma desnaturação não renaturável de suas proteínas, pois quando elas são desnaturadas pelo calor, os radicais de seus aminoácidos interagem com os radicais de outras proteínas ali presentes que também foram desnaturadas. Esse processo transforma uma substância viscosa e translúcida, constituída por unidades protéicas solúveis, como a clara do ovo previamente a fritura, em uma rede fibrosa insolúvel branca e rígida como a clara do ovo após seu aquecimento [10].

Continuando com a contextualização do conhecimento, a discussão sobre proteínas é encadeada para as implicações das alterações da conformação da proteína em nosso organismo. Foi colocado que as proteínas do leite sofrem um processo similar ao que foi realizado na aula prática, ao serem ingeridas e atingirem o meio ácido presente no estômago. O processo de alteração da estrutura protéica no estômago é ainda acentuado por ação de enzimas gástricas.

Aplicando os conceitos de estrutura e função das proteínas no organismo, pode ser discutido, por exemplo, o que aconteceria com as proteínas do leite ao ser adicionado limão (ácido), e o que ocorre com as proteínas em nosso organismo quando ingerimos limão. Esse é um momento interessante para introduzir a discussão sobre o efeito tampão do sangue e sua importância, bem como as conseqüências de uma febre alta sobre nossas enzimas.

Uma consideração final para a contextualização do conhecimento se refere a algumas doenças genéticas, em que a alteração de apenas um aminoácido da seqüência de determinada proteína pode resultar em condições clínicas importantes [2]. Nesse momento foi debatida a última forma clássica de organização das proteínas, a estrutura quaternária, a qual é resultante da união de mais de uma proteína. Foi colocado que, na anemia falciforme, por exemplo, a alteração de um aminoácido (um resíduo de glutamato é substituído por um resíduo de valina na cadeia beta da hemoglobina), quando em baixas concentrações de oxigênio, irá resultar em uma alteração da estrutura quaternária da hemoglobina, que se dissocia de tetrâmeros para polímeros, alterando a forma das hemácias e favorecendo a hemólise [1].

\footnotetext{
V ) Repasse de endereços eletrônicos na internet, relacionados ao tema, como proposta para a complementação do processo de ensino-aprendizagem iniciado em sala
} 
Para complementar o estudo das proteínas, os alunos foram orientados a navegar no site do Departamento de Bioquímica da Universidade de São Paulo <http://www.bdc.ib.unicamp.br/uploads/software/pt/versao_online/versao_online247 /estprot_v.1.3.1/programa/menu/index.html> [3]. Esse endereço foi selecionado por estar em português, contemplar o assunto abordado e apresentar o conteúdo de forma didática.

Um cuidado importante ao se propor uma prática envolvendo o uso do computador e da internet é garantir que os alunos tenham acesso a essas tecnologias. Atualmente a maioria dos alunos universitários tem acesso à internet em casa [5], bem como o contato com lojas que permitem esse acesso a um custo acessível, mas é importante também que a faculdade propicie um local para os alunos realizarem essa atividade, para que esses não se sintam excluídos dessa forma de estudo.

\section{AMOSTRA}

Como forma de avaliação da aplicabilidade da metodologia elaborada, um professor da disciplina Bioquímica Celular empregou as estratégias propostas em uma turma com 35 alunos do $2^{\circ}$ período do curso de graduação em Enfermagem de uma universidade particular da cidade de Belo Horizonte/MG. Os alunos dessa turma foram divididos em dois grupos e a metodologia repetida de forma similar em ambos, em dois dias seguidos. O tempo para a realização das três primeiras etapas da metodologia, referentes à apresentação dos modelos físicos para entendimento da estrutura de uma proteína, do uso do corpo como ferramenta pedagógica e da prática de desnaturação das proteínas do leite foi de 100 minutos. A contextualização dos conhecimentos foi iniciada durante essa primeira etapa e finalizada em uma aula seguinte de 50 minutos (realizada no mesmo dia). Ao término dessa segunda aula, os alunos foram orientados a complementarem seu estudo em casa ou nos computadores da faculdade, acessando o endereço de internet sugerido pelo professor. O link para acesso ao site foi repassado para um e-mail comunitário da turma, previamente as aulas.

Anteriormente à aplicação da metodologia os alunos já haviam tido nove aulas teóricas nas quais foram abordados os seguintes temas: polaridade, funções orgânicas e a estrutura e função dos aminoácidos. Os alunos também haviam tido duas aulas práticas: uma de introdução ao laboratório, onde conheceram os materiais utilizados no laboratório, aprenderam seu correto manuseio e normas de segurança; e uma sobre indicadores de $\mathrm{pH}$, onde foram discutidos conceitos sobre ácido-base, $\mathrm{pH} e$ curva titulação.

\section{AVALIAÇÃO DA METODOLOGIA}

Os resultados foram avaliados através do acompanhamento dialógico por parte do professor e o registro de observações e percepções durante o desenvolvimento das estratégias de ensino bem como do preenchimento, pelos alunos, de um questionário elaborado especificamente para o estudo.

As observações do professor foram registradas ao término da aula da segunda turma e as principais dificuldades ou vantagens da aplicação do método foram anotadas.

O questionário de avaliação desenvolvido para o estudo (Tabela 2), para ser respondido pelos alunos, era composto por cinco questões discursivas e foi aplicado uma semana após a realização dos procedimentos, sendo seu preenchimento feito de forma voluntária e sua identificação opcional, para permitir o livre-arbítrio dos 
estudantes na expressão de suas opiniões. As respostas escritas pelos alunos foram categorizadas e analisadas quanto a seu conteúdo.

Tabela 2: Questionário para avaliação dos resultados da metodologia proposta

Você já havia tido algum contato com o conteúdo de bioquímica: estrutura e função das proteínas anteriormente? ü Não ü Sim. Se sim escreva onde e qual a impressão você ficou sobre o tema:

O que você achou dos modelos montados em fio encapado para o estudo dos níveis de organização das proteínas?

Na prática do "Estudo qualitativo dos constituintes do leite" ficou claro para você o que ocorre com a proteína quando é adicionado ácido no leite?

Qual a importância do conteúdo de estrutura e função das proteínas para sua vida?

Há algum comentário que você gostaria de fazer?

\section{RESULTADOS E DISCUSSÃO}

\section{OBSERVAÇÕES DO PROFESSOR}

Na opinião do professor, o conteúdo pôde ser transmitido de uma forma fácil e os alunos se mostraram abertos e interessados com a exposição.

Muitos dos conceitos teóricos relacionados a um determinado conhecimento são tão complexos que dificultam o seu entendimento. O uso de modelos físicos contribuiu para a visualização de alguns construtos teóricos abordados no conteúdo. Modelos são uma analogia ao fenômeno real, elaborado para simplificar o entendimento de conceitos [11]. Existem vários tipos de modelos. Os modelos físicos são estruturas tridimensionais palpáveis utilizadas para demonstrar como um fenômeno real pode ocorrer. Como simplificações, os modelos deixam de abordar detalhes, mas descrevem o conceito aproximado da estrutura, permitindo uma melhor representação do fenômeno [11].

Um destaque positivo foi o custo para a implementação do projeto, pois foi gasto menos de $\mathrm{R} \$ 5,00$ para a compra do material e confecção dos modelos e, uma vez montados, eles podem ser arquivados para serem utilizados em outras turmas. Um cuidado importante é guardar o material em local protegido. Um problema que ocorreu entre as turmas foi uma "desnaturação" do modelo, provavelmente decorrente de algum material que foi depositado sobre ele quando ele estava armazenado em um saco plástico no laboratório.

Pode-se montar modelos com diferentes tipos de fios, utilizando fios com maior rigidez para os modelos permanentes e com menor rigidez para os modelos utilizados para demonstrações rápidas, como, por exemplo, para representar a alteração da estrutura secundária do cabelo, decorrente das interações dos átomos da proteína com as moléculas de água, quando o cabelo é molhado (Figura 1d) [1,12]. A rigidez do fio é determinada por sua secção transversa e pelo material que o compõe. Fios 
muito rígidos podem ser difíceis de moldar e fios excessivamente flexíveis podem não manter a estrutura tridimensional elaborada.

Durante a aplicação da metodologia, nem todas as respostas e informações foram dadas a priori e os alunos foram estimulados a raciocinar. Esse procedimento foi considerado positivo na opinião do professor. Ao demonstrar o primeiro modelo, constituído apenas do fio encapado sem uma conformação definida, e questionar como poderia ser a forma da proteína, os alunos foram incitados a pensar. Vygotsky [13] associa o aprendizado a um processo ativo de resolução de um problema. A apresentação da molécula protéica tridimensional pura e simplesmente tiraria a chance dos alunos desenvolverem o raciocínio e acompanharem a construção do conhecimento. Durante a prática de desnaturação do leite as respostas foram, novamente, instigadas a serem elaboradas. É conveniente que o aluno faça pesquisa, reflita sobre o conteúdo, possa fazer suposições, experimentos, discutir e argumentar com seus colegas e não simplesmente aja conforme a determinação de uma autoridade externa, aguardando passivamente suas respostas. No procedimento foram observadas diversas respostas incorretas. Todavia, tais respostas foram consideradas importantes para o transcorrer da aula, na opinião do professor, pois fizeram parte do processo de aprendizado do aluno. Trabalhar com os erros é importante, pois em situações reais da vida o erro estará presente. É interessante para o ensino que os alunos se tornem cada vez mais capazes de interpretar as situações de forma autônoma e crítica, com iniciativas suficientes para sanar suas dúvidas. O ensino-aprendizagem deve ser um processo interativo, em que o aluno deve apresentar um papel ativo [14].

A analogia das ligações covalentes com as mãos dadas e da conversa com as interações intramoleculares, realizado na parte de uso do corpo como ferramenta pedagógica, ajudou no entendimento dos conceitos de ligação covalente e força de Van Der Waals. O professor ilustrou essa constatação exemplificando que um aluno escutando as explicações sobre ligações peptídicas nos termos bioquímicos apropriados questionou se essas correspondiam às mãos dadas. Verifica-se que nem todos os alunos dominam os conhecimentos básicos de química, sendo necessário ao professor fazer uma revisão dos mesmos a fim de facilitar a compreensão do assunto que será abordado na disciplina [6].

Vivenciamos a era da informação, um período em que a propagação do conhecimento tornou-se mais rápida que os meios físicos para a sua transmissão [15]. Novas tecnologias colocam em descompasso as formas tradicionais de ensino frente às novas linguagens que o aluno se depara no seu dia-a-dia. Essas transformações modificam a maneira de se apreender o mundo e construir o conhecimento [5]. O professor que realizava as observações relatou que não foi capaz de avaliar de forma precisa o impacto do uso da internet na formação dos alunos, todavia, a disposição eletrônica de conteúdos e a utilização dos recursos de informática como complementação aos estudos, exerce um papel importante na busca de conhecimento e no acesso irrestrito às informações [16]. O objetivo do uso da internet como ferramenta de ensino foi apoiar, ampliar e complementar o trabalho da sala de aula, que não deve ser percebida ou aceita como único espaço ou foro de aprendizagem. Esta nova metodologia exige uma maior participação dos estudantes, superando o papel de mero expectador, conduzindo o aluno para agente em seu processo de aprendizagem. O uso da internet permite ao aluno programar seus horários de estudo, aprendendo a aprender [5]. O uso da internet fica como sugestão, apesar da dificuldade de análise de sua contribuição real na formação do aluno observada na metodologia proposta para este estudo. 


\section{RESPOSTAS DOS QUESTIONÁRIOS APLICADOS AOS ALUNOS PARA AVALIAÇÃO DA METODOLOGIA}

Dezoito alunos, em uma turma de 35, responderam o questionário. Dois alunos dentre os que responderam optaram por não se identificar. Os questionários respondidos foram numerados de forma aleatória e os alunos foram identificados pelo número atribuído ao seu relatório. Todos os respondentes foram tratados no texto a seguir por substantivos masculinos, independentemente do gênero. Dois alunos dos que se identificaram eram do sexo masculino e 14 do feminino.

Onze alunos relataram já ter tido algum contato com o conteúdo de estrutura e função das proteínas, tendo esse contato ocorrido em momentos distintos, como: durante o ensino médio, no mesmo curso de graduação em outra faculdade, em outro curso de graduação na mesma universidade, em outra disciplina da graduação ou durante o cursinho pré-vestibular. A maioria dos alunos que relataram já ter tido algum contato com a bioquímica consideraram a matéria interessante, relacionada a outros conteúdos e que gostaram do assunto, a despeito de suas dificuldades e temores iniciais. Dois alunos, dos que assinalaram já ter tido um contato inicial com a matéria, relataram ter achado seu conteúdo difícil e que não foram capaz de entendêla nesse primeiro contato que tiveram anteriormente.

A análise dos conceitos prévios que os alunos têm a respeito de uma disciplina evidencia a impressão que os mesmos possuem a respeito dos conteúdos que serão ministrados e pode auxiliar na determinação das estratégias a serem utilizadas em sala de aula. Alunos interessados podem se mostrar mais motivados para estudar e, assim, assimilarem o conteúdo com maior facilidade. No presente estudo, em uma amostra de 18 alunos voluntários já é possível identificar a heterogeneidade de uma classe, pois, ao mesmo tempo em que alguns consideraram que nunca haviam tido contato com o conteúdo, outros disseram ter tido contato e gostado e, ainda, outros relataram que haviam tido contato com a matéria, mas ficaram com uma impressão negativa. Em um contexto de ensino-aprendizagem, cada um dos elementos que participa desse processo trás uma bagagem própria, uma história pessoal, interesses e dificuldades individuais [14]. O professor deve ficar atento para essas disparidades presentes em uma turma ao planejar suas aulas.

Os alunos que responderam aos questionários foram unânimes em elogiar os modelos elaborados para a visualização do conteúdo teórico. Foram expressas observações como:

"Achei muito interessante, pois contribui para o aprendizado e facilitou a visualização da estrutura estudada". Aluno 5

"Muito interessante, criativo e fácil de entender". Aluno 6

Um aluno (Aluno 10) relatou que "foi bom" visualizar o conteúdo através dos modelos e que "estava bem explicado", entretanto, ressaltou que não conseguiu entender muito bem ("apesar de que eu não entendi muito bem"). É importante lembrar também que, como alguns alunos não preencheram o questionário, as avaliações negativas ou dificuldades de entendimento podem ter sido subestimadas.

Santos e Anacleto [6], em um estudo com 120 alunos de diversos cursos da área biológica, observaram que $95 \%$ dos alunos apresentaram dificuldades consideráveis no entendimento do conteúdo de bioquímica. 
Essa mesma dificuldade de compreensão do conteúdo pôde ser identificada nas respostas de dois alunos à questão referente à clareza de entendimento da prática de proteínas do leite. O Aluno 3 descreveu corretamente os resultados observados no experimento, mas em seguida acrescentou: "não sei se é exatamente assim mesmo". O Aluno 10 também expressou suas dificuldades de entendimento, agora com relação à parte prática da metodologia proposta. Os demais alunos afirmaram que ficou claro o que ocorre com as proteínas quando o ácido acético é adicionado no leite.

Num contexto de sala de aula, em que, além das expectativas, podemos encontrar alunos com bagagens teóricas distintas com relação ao conteúdo que será lecionado e com ritmos diferentes de assimilação do conteúdo durante uma mesma atividade, é importante que o professor utilize métodos de ensino auxiliares como uma alternativa para minimizar esses problemas. A monitoria tem sido amplamente utilizada pelas universidades como uma forma de assistência no processo de ensino e, apesar de boa parte dos alunos só recorrerem a ela em vésperas de avaliações, a maior parte deles acredita que a monitoria constitui um instrumento importante para seu aprendizado [6].

Outras estratégias podem também ser buscadas para minimizar essa disparidade de progressão no entendimento, como a realização de exercícios em grupo. Os exercícios possibilitam aos alunos discutirem entre si e nivelarem seus conhecimentos. A proposta de realização de exercícios para fixação da matéria foi, inclusive, sugerida pelo Aluno 12 no último item do questionário, destinado a comentários:

"As aulas de bioquímica possuem um conteúdo muito extenso para ser dado em pouco tempo. No entanto, as aulas são muito práticas e não são pesadas. Acredito também que exercícios são muito importantes para a compreensão da matéria."

Uma sexta estratégia pode ser incluída na metodologia de ensino proposta, a aplicação de exercícios posteriormente à realização das etapas iniciais descritas na metodologia. A aplicação de exercícios auxilia a solucionar as dúvidas, minimizar as dificuldades de compreensão remanescentes durante o processo de ensinoaprendizagem e consolidar o conteúdo de estrutura e funções das proteínas.

A quarta pergunta direcionada aos alunos foi relativa ao que ele havia visto de relevante para sua vida no estudo da estrutura e função das proteínas. Vale observar que a relevância de muitos dos conteúdos trabalhados nos primeiros períodos do 30 grau não pode ser prontamente reconhecida ou percebida pelos alunos uma vez que muitas das relações ainda não foram estabelecidas com conteúdos que serão futuramente estudados. Cabe, freqüentemente, ao professor o papel de depositário de confiança que ele está trabalhando conteúdos fundamentais para a formação do profissional que se pretende ser. O Aluno de número 15 relatou que ainda não conseguiu assimilar a importância do conteúdo de estrutura e função das proteínas. Por outro lado, dezesseis alunos $(88,9 \%)$ relataram que consideraram o conteúdo apresentado importante para o seu futuro profissional e/ou para o entendimento de outras matérias.

Segundo Oliveira et al [9], devido às transformações sociais e ao desenvolvimento tecnológico na área, há uma nova percepção a respeito do conteúdo das disciplinas básicas como bioquímica. Em uma turma do primeiro período do curso de graduação em odontologia, mais de $80 \%$ dos estudantes entrevistados consideraram que essa matéria é relevante para a sua formação.

Um aluno do presente estudo (Aluno 1) relatou que está descobrindo a importância "durante a matéria", o que corrobora para o papel da metodologia utilizada, dentre outros fatores, para a assimilação da relevância do conteúdo. 
A última pergunta discursiva foi aproveitada pelos alunos para realizarem críticas e elogios ao professor, bem como para a exposição de algumas percepções a respeito da metodologia empregada, como pode ser observado nos comentários transcritos a seguir:

"Eu acho que se manter a aula da mesma maneira que está e com os exemplos e modelos citados, a aula fica bem produtiva e de fácil compreensão". Aluno 17

"Comparo as aulas de bioquímica com aprender a ler, antes olhávamos o livro (corpo), mas não sabíamos lê-lo, agora, através da bioquímica aprendemos as letras que, junto à fisiologia nos contam a história". Aluno 16

\section{CONSIDERAÇÕES FINAIS}

O presente estudo teve o anseio de desenvolver uma metodologia para facilitar o ensino da estrutura e da função das proteínas e analisar sua aplicabilidade. Não foi objetivo do estudo atual avaliar a efetividade do aprendizado do conteúdo com o uso da metodologia.

Comparando-se as respostas dos questionários com as observações apresentadas pelo professor, é possível perceber que houve uma impressão positiva de um modo geral com a metodologia proposta. As respostas observadas foram positivas e motivadoras para os diversos participantes envolvidos no processo de ensinoaprendizagem (professor e alunos). A motivação é um estimulo para a aprendizagem e, assim, os autores do presente artigo recomendam o uso dessa metodologia caso o professor a identifique com seus atributos pedagógicos. O ensino é um processo de interação entre professor e aluno e, como cada indivíduo é único, a interação entre esses seres singulares também assim o será. O professor tem a liberdade de optar por diferentes metodologias de ensino, considerando suas características, as características da turma em que está lecionando e a interação entre eles, bem como a liberdade de adaptar essas metodologias para buscar obter melhores resultados no processo de ensino-aprendizagem desenvolvido. Os professores de disciplinas básicas devem utilizar técnicas que estimulem os alunos a aprender e devem aplicar os conhecimentos da forma mais clara possível para promover o seu melhor aproveitamento [9].

As estratégias elaboradas inicialmente, apesar de terem sido bem acolhidas pela maioria dos alunos, não esclareceram o conteúdo de forma universal, sendo que alguns alunos podem ter ficado com déficits em seu entendimento. A aplicação de questionários como forma de avaliar a metodologia de ensino inverte uma situação normalmente realizada em sala de aula, na qual os alunos é que são avaliados. Essa inversão foi positiva e permitiu ao professor analisar como estava a assimilação do conteúdo de acordo com a percepção dos alunos. Essa investigação permite ao estudante expor suas dificuldades, que, do contrário, poderiam passar despercebidas.

Entretanto, a simples apuração da existência de dificuldades não é suficiente para a resolução do problema. Também devem ser tomadas medidas para sua solução. Exercícios sobre a estrutura e função da proteína podem ser propostos como forma de complementar a metodologia inicial. A realização de monitorias para assistência individualizada aos alunos é sugerida também. Apesar de não ser possível garantir o entendimento completo para todos os alunos, é função do professor tentar fazê-lo da melhor maneira possível e utilizando todas as estratégias que julgar necessária. 
Há uma variedade de estratégias de ensino à disposição do docente. O uso adequado dessas estratégias implica na seleção intencional e diretiva das que melhor funcionam como mediadoras e facilitadoras do processo de ensino-aprendizagem. A escolha de metodologias que despertem o interesse e a curiosidade dos alunos pelos processos bioquímicos pode fazer uma grande diferença na relação professor-aluno e no processo de aprendizagem. As metodologias empregadas no ensino de bioquímica, do fio ao computador, podem resultar em uma imagem mais positiva da disciplina e contribuir para uma maior motivação e compreensão por parte do aluno.O simples relato do uso de estratégias alternativas e o julgamento do processo pelos atores nele envolvidos, podem servir de base e incentivo para que outros profissionais possam ousar por este e por outros caminhos na busca de aperfeiçoamento de suas práticas docentes e suas relações com o saber. O presente estudo buscou desenvolver ferramentas adicionais para os professores de bioquímica trabalharem o caminhar autônomo de seus alunos rumo ao conhecimento. Os alunos que aprendem a pensar se tornam capazes de julgar e tomar decisões próprias, tornando-se, assim, livres para decidirem seu caminho [17].

\section{REFERÊNCIAS BIBLIOGRÁFICAS}

[1] Nelson, David L. and Michael M. Cox. (2005) Lehninger principles of biochemistry, 4ed. W.H. Freeman \& Co, New York.

[2] Stryer, L. (2002). Biochemistry, 5a Ed. W.H. Freeman \& Co, New York.

[3] Departamento de Bioquímica da Universidade de São Paulo <http://www.bdc.ib.unicamp.br/uploads/software/pt/versao_online/versao_online247 /estprot_v.1.3.1/programa/menu/index.html> (consultada em 2007)

[4] Moreira, L. M. (2007) O uso do corpo como ferramenta pedagógica: um modelo alternativo que desconsidera a ausência de recursos específicos para o ensino de bioquímica e biologia molecular no ensino fundamental Revista Brasileira de Ensino de Bioquímica e Biologia Molecular, Artigo 4, Edição 01. Disponível em:

<http://www.bdc.ib.unicamp.br/rbebbm/visualizar_material.php?id_material=475>. Acesso em: 04 nov. 2007.

[5] Amaral, C. L. C., Figueira, r. C. L., et al. (2006) A utilização de ambientes virtuais no ensino de bioquímica: um estudo de caso na UNICSUL. Revista Brasileira de Ensino de Bioquímica e Biologia Molecular, Artigo 1, Edição 01. Disponível em:

<http://www.bdc.ib.unicamp.br/rbebbm/visualizar_material.php?id_material=161>. Acesso em: 02 set. 2007.

[6] Santos, V. T., Anacleto, C. (2007) Monitorias como ferramenta auxiliar para aprendizagem da disciplina bioquímica: uma análise no Unileste-MG Revista Brasileira de Ensino de Bioquímica e Biologia Molecular, Artigo 5, Edição 01. Disponível em: <http://www.bdc.ib.unicamp.br/rbebbm/visualizar_material.php?id_material=402>. Acesso em: 02 set. 2007.

[7] Paulo F. (1976) Ação cultural para a liberdade e outros escritos. Paz e Terra, São Paulo.

[8] Molander B-O.; Halldén O.; Pedersen S. (2001) Understanding a Phenomenon in Two Domains as a Result of Contextualization. Scandinavian Journal of Educational Research, v. 45, n.2, pp. 115-123 
[9] Oliveira, R. C., Iano, F. G., Silva, T. L., et al. (2006) Percepção dos Alunos do Curso de Odontologia de uma Universidade Brasileira em Relação à Importância da Disciplina de Bioquímica na sua Profissão Revista Brasileira de Ensino de Bioquímica e Biologia Molecular, Artigo 2, Edição 01. Disponível em:

<http://www.bdc.ib.unicamp.br/rbebbm/visualizar_material.php?id_material=346>. Acesso em: 02 set. 2007.

[10] Sumanas, Inc:

<http://www.sumanasinc.com/webcontent/anisamples/nonmajorsbiology/proteinstruc ture.html> (consultada em 2007)

[11] Portney, L. G., Watkins, M. P. (2000) Foundations of clinical research applications to pratice. Prentice-hall, New Jersey.

[12] Better Hair Through Chemistr <http://www.exploratorium.edu/exploring/hair/hair_activity.html > (consultada em 2007)

[13] Vygotsky, L. S. (1991) Pensamento e linguagem 3a. Edição. São Paulo: Martins Fontes.

[14] Moretto, R.; Mansur, O. C. (2000). Ser professor: as múltiplas dimensões da docência. Revista Brasileira de Educação Médica. Rio de Janeiro. v.24, no 2, maio/set., pp 5-8.

[15] Singer, K. P.; Tan, B. K. (2000) Navigating the internet maze. Man Ther, v. 5, $\mathrm{n}^{\circ}$ 3, pp. 165-72.

[16] Souza, K. A. F. D., Neves, V. (2006) A. Bioquímica de Alimentos na web: proposta de um site de apoio às aulas experimentais presenciais ou à distância Revista Brasileira de Ensino de Bioquímica e Biologia Molecular, Artigo 4, Edição 02. Disponível em: <http://www.bdc.ib.unicamp.br/rbebbm/visualizar_material.php?

id_material=185>. Acesso em: 02 set. 2007.

[17] Piaget, J. (1994) A educação da liberdade. Conferencia apresentada no $28^{\circ}$ Congresso Suíço de Professores, Berna. 